\title{
Deposition of melanin and iron in ocular structures in haemochromatosis
}

\author{
GEOFFREY DAVIES, $\dagger$ IAIN DYMOGK, $\ddagger$ JOHN HARRY, * \\ AND ROGER WILLIAMS $\ddagger$
}

$\dagger$ Department of Ophthalmology and the \pm M.R.C. Group on Metabolism and Haemodynamics of Liver Disease, King's College Hospital, London, and the *Department of Pathology, Institute of Ophthalmology, University of London

Cutaneous pigmentation is a well-recognized feature of idiopathic haemochromatosis and, in various series, has been recorded in up to 80 per cent. of patients (Finch and Finch, I955). In the world literature there are occasional reports of pigmentation in the gums (Saundby, I890), buccal mucous membranes (Richardière, I895), lips (Parker, I903), and tongue (Hess and Zürhelle, I905), and Maddox (1933) recorded the presence of discolouration around the disc margin of the retina in four patients with haemochromatosis. The past finding was also observed by Hudson (1953) in one of the five patients he examined. Apart from these reports, however, abnormal pigmentation in the eye has received little attention. In this paper we describe findings related to the occurrence and distribution of melanin and iron in the extraocular structures and within the eye, in haemochromatosis, based on a study of 44 patients.

\section{Patients}

Of the 44 patients examined, 42 had primary idiopathic haemochromatosis, defined according to the criteria of Williams (1968), and the other two had alcoholic cirrhosis with secondary iron overload. All 44 patients were of the Caucasian race.

\section{Methods}

Pigmentation of the conjunctiva and lid margins was looked for using direct slit-lamp examination, and a careful search was made for pigmentation in the cornea, uvea, lens, and retina. Ocular photographs were taken with a coupled Zeiss-Ikon camera using high-speed Ektachrome film.

\section{Results}

CONJUNGTIVAL PIGMENTATION

Brown pigmentation of the conjunctiva was detected in eight patients. The pigment was present in the bulbar conjunctiva and was confined to the area adjacent to the limbus, encroaching on to the cornea. It was most marked along the inferior border of the limbus extending to the medial aspect of the globe opposite the interpalpebral fissure. Some pigmentation was also detected along the superior border of the limbus. The deposits of pigment in the conjunctiva tended to be given a radial striation by the intervening lymphatic channels, while in one patient horizontal striae were seen which were probably due to the mechanical effects of rucking of the conjunctiva with movements of the lower lid (Fig. I, opposite). 

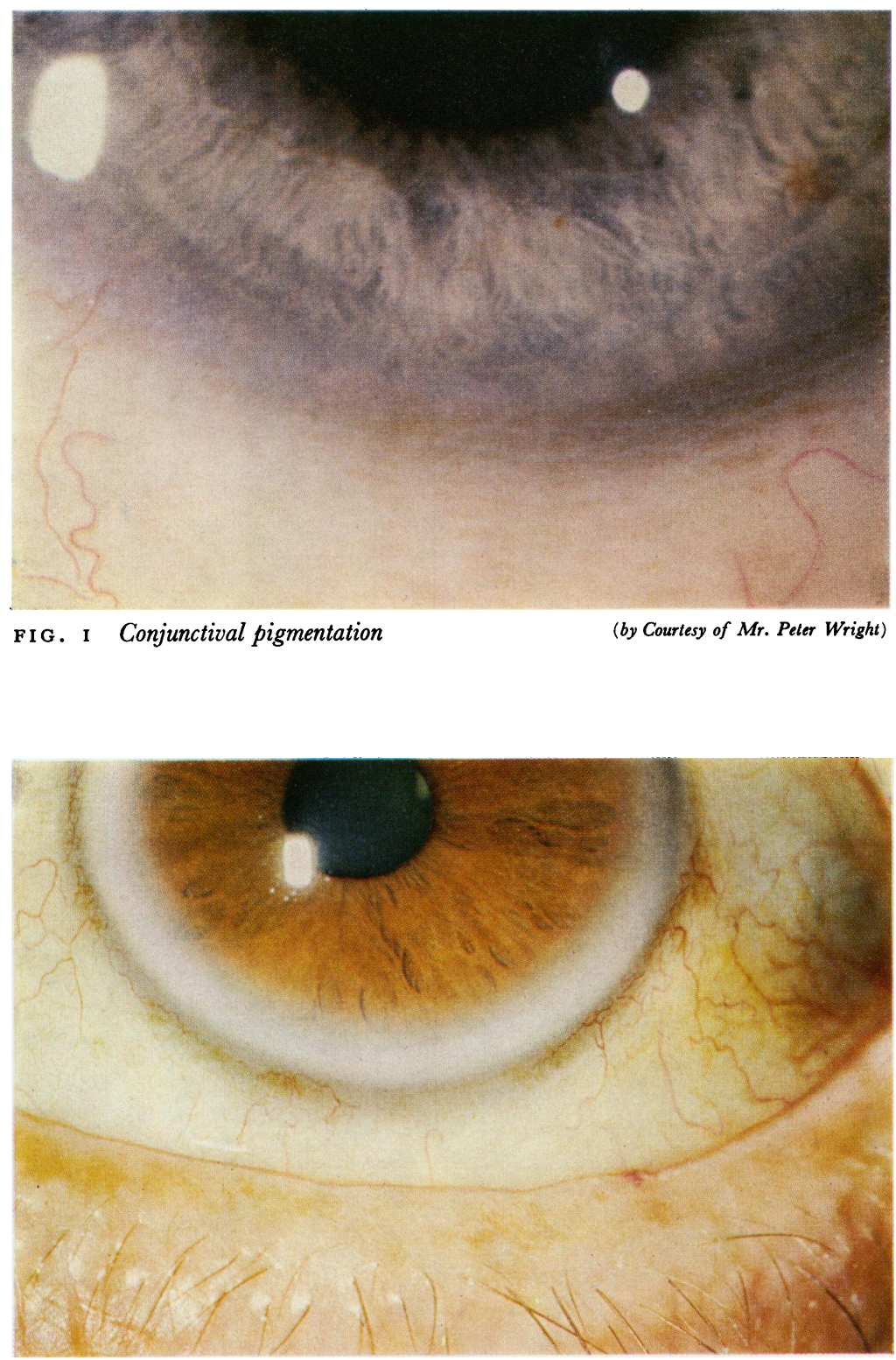

FIG. 3 Pigmentation of lid margin

To face page $33^{8}$ 
A biopsy of the affected conjunctiva was performed in one patient (Case 2). Microscopy showed the presence of melanin pigment, particularly in the basal layers of the epithelium (Fig. 2), while a Perls-stained section demonstrated the presence of a minute amount of free ferric iron, mainly within the epithelium.

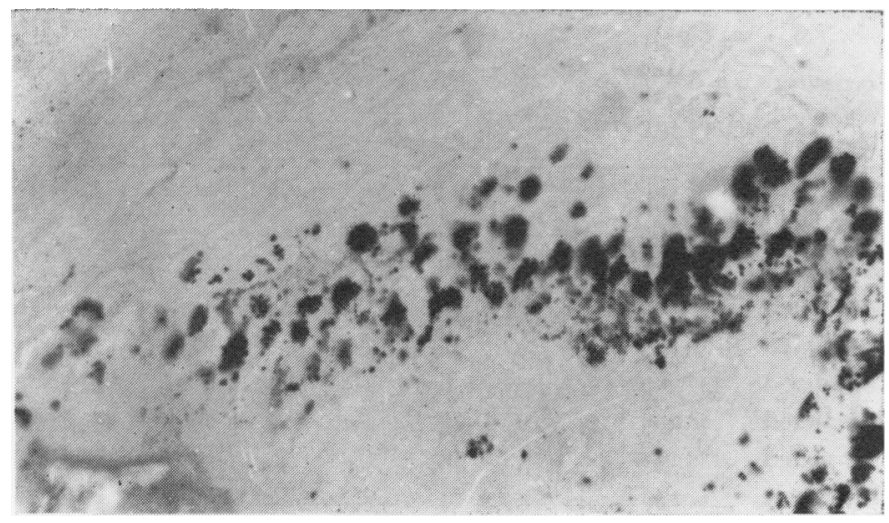

FIG. 2 Section of conjunctiva to show melanin pigment in epithelium. Fontana $\times 570$

LID PIGMENTATION

A similar brown pigmentation of the lid margin was present in nine patients. It was seen throughout the length of the margin, being more prominent around the lash follicles. The pigmentation was confined to the cutaneous side of the muco-cutaneous junction and was present in both the upper and lower lids, being more apparent in the latter (Fig. 3, see col. pl.). Four of these patients also showed pigmentation of the conjunctiva.

One patient (Case I2), an alcoholic with cirrhosis and secondary siderosis, in whom lid pigmentation was present, subsequently died from rupture of oesophageal varices. A wedge-shaped portion of the lower lid was removed at autopsy. Histological examination of this tissue revealed increased melanin pigmentation, particularly within the basal layers of the epithelium of the skin (Fig. 4), but no free iron could be detected.

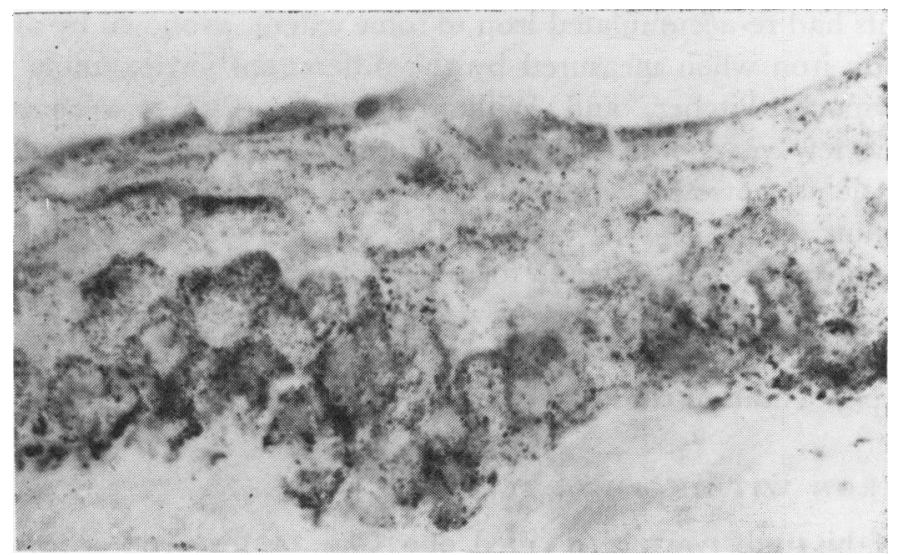

FIG. 4 Section of lid to show melanin pigment in epithelium of skin Fontana $\times 570$

RElation of Pigmentation to glinigal status (Table, overleaf)

Five of the patients with idiopathic haemochromatosis and the two patients with alcoholic cirrhosis and secondary iron overload were either untreated or had been only partially 
Table Clinical and biochemical details of thirteen patients with pigmentation of extraocular structures

Cases I-I I had idiopathic haemochromatosis

Cases $12-13$ had alcoholic cirrhosis with secondary siderosis

\begin{tabular}{|c|c|c|c|c|c|c|c|c|c|}
\hline \multirow{2}{*}{$\begin{array}{l}\text { Case } \\
\text { no. }\end{array}$} & \multirow{2}{*}{$\begin{array}{l}\text { Age } \\
(y r s)\end{array}$} & \multirow{2}{*}{ Sex } & \multirow{2}{*}{$\begin{array}{l}\text { Venesection } \\
\text { therapy }\end{array}$} & \multirow{2}{*}{$\begin{array}{l}\text { Serum } \\
\text { iron } \\
(\mu g . / \text { roo } m l .)\end{array}$} & \multirow{2}{*}{$\begin{array}{l}\text { Saturation } \\
\text { of serum } \\
\text { TIBC } \\
\text { (per cent.) }\end{array}$} & \multirow{2}{*}{$\begin{array}{l}F v \\
(\mu g . / k g .) \\
\dagger\end{array}$} & \multicolumn{3}{|l|}{ Pigmentation } \\
\hline & & & & & & & Conjunctiva & Lids & Skin \\
\hline I & 60 & $\mathbf{M}$ & None & 140 & 82 & 2419 & + & + & + \\
\hline 2 & 53 & $\mathbf{M}$ & In progress & 265 & 98 & I 726 & + & + & + \\
\hline 3 & 45 & $\mathbf{M}$ & In progress & 335 & 99 & 713 & + & o & $++t$ \\
\hline 4 & 59 & $\mathbf{M}$ & Completed & 70 & 26 & 822 & + & + & +++ \\
\hline 5 & 46 & $\mathbf{M}$ & Completed & I 35 & 96 & 711 & + & + & ++ \\
\hline 6 & 50 & $\mathbf{M}$ & Completed & 260 & 96 & 484 & o & + & + \\
\hline 7 & $6 o$ & $\mathbf{F}$ & Completed & 205 & 93 & 319 & o & + & $+t$ \\
\hline 8 & 65 & $\mathbf{M}$ & Completed & 245 & 98 & 90 & + & o & o \\
\hline 9 & 63 & $\mathbf{M}$ & Completed & 140 & 74 & 560 & o & + & + \\
\hline Io & $5^{I}$ & $\mathbf{M}$ & Completed & 270 & 100 & $66 \mathrm{I}$ & + & o & + \\
\hline II & 39 & $\mathbf{M}$ & Just completed & 50 & I3 & 79 & + & o & + \\
\hline 12 & 47 & $\mathbf{M}$ & None & I 50 & 94 & - & o & + & ++ \\
\hline I 3 & 64 & $\mathbf{M}$ & None & 220 & 94 & $4^{16}$ & o & + & +++ \\
\hline
\end{tabular}

* TIBC-Total iron binding capacity

† Fv -A measure of the total chelatable body iron estimated by the differential ferrioxamine test. Normal range $0-300 \mu \mathrm{g} . / \mathrm{kg}$. (Smith and others, 1969 ).

treated by venesection therapy. Of these, one had conjunctival pigmentation and two lid pigmentation, the other two having pigmentation at both sites. The remaining 37 patients had been treated by venesection therapy and eight of them had pathological pigmentation distributed as follows: conjunctivae alone-three; lid alone-three; both sites-two. With the exception of Case 8, who had bled recently from a duodenal ulcer, each of these patients had re-accumulated iron to some extent, as shown by an increase in total chelatable body iron when measured by the differential ferrioxamine test (Smith, Lestas, Miller, Dymock, Pitcher, and Williams, I969). This re-accumulation had occurred during the few years which had elapsed since the completion of venesection therapy. Other patients, however, who had re-accumulated iron to a similar extent did not show pigmentation.

Although skin pigmentation is difficult to assess, in general the patients with either conjunctival or lid pigmentation also showed prominent skin pigmentation. One of the untreated patients had prominent skin pigmentation and, in spite of a careful search, no lid or conjunctival pigmentation could be detected.

DEPOSITION OF IRON WITHIN THE EYE

During the course of this study two patients died, one (Case 12) from rupture of oesophageal varices, and the other, a man of 70 with primary haemochromatosis, from liver failure. An eye removed post mortem from Case 12 was examined histopathologically and showed, on a Perls-stained section, the presence of minute traces of free ferric iron in the corneal epithelium and in the non-pigmented epithelium of the ciliary body. Similar amounts of 
iron with the same distribution were found in both eyes of the other patient who died, the iron in the corneal epithelium being present mainly in the limbal region and extending into the conjunctiva; bleached sections of these eyes also showed the presence of a minute trace of free iron within the epithelium of the iris.

\section{Discussion}

Although conjunctival pigmentation was reported in two patients with idiopathic haemochromatosis by Ridder ( 1910 ), pigmentation of the lid has not previously been described. The slate-coloured pigmentation around the disc margin, observed by Maddox (1933) in four patients and in one of five patients by Hudson (1953), was not seen in the present series of cases of idiopathic haemochromatosis, although one of the two with secondary haemochromatosis (Case I2) had a faint halo-like pigmentation around the disc margin. Hudson also described a brownish-green discolouration of the iris in his patients, which we have not seen, and it is of interest that neither he nor Maddox described the pigmentation of the lids and conjunctivae which was such a striking feature of our patients.

The cutaneous pigmentation of patients with idiopathic haemochromatosis usually diminishes with venesection therapy (Williams, Smith, Spicer, Barry, and Sherlock, I969). The most marked ocular pigmentation in our patients was in those who were either untreated or had been only partially treated, and it was less frequently found in patients who had been subjected to previous venesections. This would suggest that the pigmentation in the two sites has a similar pathogenesis. The mechanism of cutaneous pigmentation in haemochromatosis has, however, not been determined. It has been suggested that the iron present in the cutaneous tissues may favour the deposition of melanin by increasing the progressive oxidation of the amino acid tyrosine (Robert and Zürcher, i96o), a feature of normal melanogenesis (Brunet, I96o; Fitzpatrick, Seiji, and McGugan, I96r). Disorders of the endocrine system are known to affect skin pigmentation, for example in Addison's disease, and there is some evidence from animal studies that oestrogens increase skin pigmentation (Bischitz and Snell, 1960), although androgens have no such effect (Bischitz and Snell, 1959). The response of the adrenal cortex to ACTH is normal in haemochromatosis, but these patients usually have hypogonadism. Whether the skin pigmentation in haemochromatosis is due to a disordered hypothalamic-pituitary axis, to hyperoestrogenism consequent upon impaired hepatic inactivation, or to other factors remains to be determined (Harris, I969).

Although the mechanism of the ocular pigmentation is not clear, it seems likely that it represents an extension of the pigmentary phenomena seen in other sites, and it was therefore of some inter est to find lid and conjunctival pigmentation similar to that observed in haemochromatosis in a patient with Addison's disease who had no demonstrable disturbance of iron metabolism. We have also seen similar pigmentation in the lids after sunburn and in the conjunctivae of coloured races.

While the deposition of iron in various organs of the body is the outstanding characteristic of haemochromatosis, the presence of iron within the eye has not, as far as we are aware, been previously reported. It is of interest that this iron, which for the eye can be considered to be of endogenous origin, was found in the corneal epithelium and ciliary body epithelium, which are two of the characteristic sites of iron deposition in siderosis bulbi, a condition in which iron infiltrates the tissues either from a retained intraocular foreign body or from an intraocular haemorrhage. 


\section{Summary}

A systematic ophthalmic examination of 44 patients with haemochromatosis revealedô pigmentation of the conjunctiva or lid margin in thirteen (29 per cent.). This pigmenta- $\vec{\Rightarrow}$ tion was present in three of five untreated patients with idiopathic haemochromatosis and in both patients with secondary haemochromatosis who were also untreated, whereas only등 eight of the 37 patients who had previously completed venesection therapy showed pig- $\frac{\overline{\bar{N}}}{\overline{\frac{D}{2}}}$ mentation. Histopathological examination of three eyes removed at autopsy showed the $\stackrel{\mathbb{D}}{\stackrel{\mathbb{R}}{ }}$ presence of iron within the corneal epithelium and in the ciliary body, and this is the first time that this has been recorded.

We are indebted to Mr. V. J. Elwood of the Department of Pathology, Institute of Ophthalmology, for technical assistance, and to Mrs. E. P. Burr for secretarial help.

\section{References}

BISCHITZ, P. G., and SNELl, R. S. (I959) 7. invest. Derm., 33, 299 (1960) 7. Endocr., 20, 312

BRUNET, P. C. J. (I960) "Melanogenesis", in "Progress in the Biological Sciences in Relation to

Dermatology", ed. A. Rook, p. I5. Cambridge University Press, Cambridge

FINCH, s. C., and FINCH, C. A. (I955) Medicine (Baltimore), 34, $3^{8}$ I

FitzPatrick, т. B., SEiji, M., and McGugan, A. D. (196i) New Engl. J. Med., 265, 328

HARRIS, P. W. R. (I969) Guy's Hosp. Rep., I 18, 387

Hess, O., and zURHElle, E. (I905) Z. klin. Med., 57, 344

HUDSON, J. R. (1953) Brit. 7. Ophthal., 37, 242

MADDOX, K. (1933) Ibid., 17, 393

PARKER, G. (I903) Brit. med. J., 2, 1052

richardière, H. (i 895) Un. méd (Paris), 4 sér., r, 577

RIDDER, м. (I9IO) Dtsch. med. Wschr., 36, I647

ROBERT, P., and ZÜRCHER, H. (1950) Dermatologica (Basel), roo, 2 I 7

SAUNDBY, R. (1890) Brit. med J., 2, I 457

SMith, P. M., LeStAS, A. M., Miller, J. P. G., DYMOck, I. W., Pitcher, C. S., and Williams, R. (I969)

Lancet, 2, 402

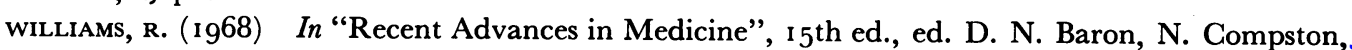
and A. M. Dawson, p. I 70. Churchill, London SMITH, P. M., SPICER, E. J. F., BARRY, M., and SHERlock, s. (I969) Quart. J. Med., 38, I 